\title{
A construção da lógica do sistema numérico por uma criança com Síndrome de Down
}

\section{The construction of logical numerical system by a child with Down Syndrome}

\author{
Maria Helena Fávero* \\ Denise de Oliveira**
}

\begin{abstract}
RESUMO
Por meio de um estudo de caso, desenvolvido em 3 fases, focou-se a criança com Síndrome de Down e o desenvolvimento de suas estruturas lógico-matemáticas, particularmente aquelas referentes à lógica do sistema numérico. Primeiro, avaliaram-se as competências matemáticas do sujeito com SD e as suas dificuldades. Depois, desenvolveu-se uma intervenção psicopedagógica, cujas sessões, registradas em vídeo e analisadas, explicitaram a seqüência das ações do sujeito, o significado destas ações em relação às suas aquisições conceituais e a importância da mediação nesse processo. Finalmente, reavaliou-se o sujeito. Os resultados indicam que o desenvolvimento cognitivo do sujeito com SD obedece às mesmas etapas descritas por Piaget, sendo harmonioso, repetitivo e mais lento, apresentando uma certa "rigidez", de modo que a evolução de uma etapa de desenvolvimento a outra necessita de uma mediação adequada do meio. Indicam ainda: a preocupação do sujeito em dar a resposta supostamente correta nas situações-problema e a ansiedade decorrente em terminá-la em curto tempo; a importância de se considerar as singularidades do indivíduo na escolha do material psicopedagógico. Ficou evidenciado que a intervenção psicopedagógica possibilitou a construção de novas estruturas cognitivas e a ampliação dessas estruturas em competências a serem utilizadas na resolução das situações-problema; possibilitou uma modificação global no pensamento lógico do indivíduo e o desenvolvimento do
\end{abstract}

\footnotetext{
*Instituto de Psicologia da Universidade de Brasília, DF. E-mail: faveromh@unb.br

** Divisão de Ensino Especial da Secretaria de Educação do DF, Brasília, DF.
} 
pensamento metacognitivo; é valiosa como procedimento de pesquisa pois tanto evidencia as particularidades do desenvolvimento na aquisição do conhecimento como gera dados para a avaliação da intervenção e para o aconselhamento de pais e professores.

Palavras-chave: desenvolvimento cognitivo, estruturas lógico-matemáticas, Síndrome de Down.

\begin{abstract}
Our research was focused on the development of logical-mathematical structures and, particularly, on the construction of the logic of the numerical system, through a case study, involving a subject who suffers from Down Syndrome. We have collected data during three moments. First, we evaluated the mathematical competencies and difficulties of the subject. Next, we developed a series of sessions, which were recorded on video. We evaluated the videos thoroughly, making the subject's sequence of actions explicit, clarifying the meaning of these actions in relation to the acquisition of conceptual structures and identifying the importance of mediation for the process. Finally, we reevaluated the subject. The results have indicated that the subject's cognitive development follows the stages described by Piaget, being harmonious, repetitive and time demanding; each stage will only evolve through an appropriate mediation of the environment. Moreover, we have also observed the subject's concern about giving the answer that was supposedly correct. The psychopedagogical intervention has favored the subject with the construction of new cognitive structures and the amplification of these structures into competencies as a means to use them in problem-solving situations. We have also verified a global modification of the subject's logical reasoning and the development of metacognitive reasoning. We can say that the psychopedagogical intervention may be used as a valuable research method, for it favors the identification of specific developmental particularities of the process of knowledge acquisition.

Key-words: cognitive development, logical-mathematical structures, Down Syndrome.
\end{abstract}




\section{A construção da lógica do sistema numérico por uma criança com Síndrome de Down}

Como se sabe, a história da Psicologia do Desenvolvimento Humano tem uma relação estreita com a teoria da evolução de Darwin. Hoje é consenso a defesa de que o texto Biografia de uma criança, escrito por Darwin em 1877, inaugurou o estudo do desenvolvimento psicológico como um campo específico de estudo, e que se trata do mais antigo texto moderno da Psicologia da criança. Nele, um estudo de caso abrangendo as áreas motora, emocional, comunicativa, intelectual e o desenvolvimento moral, Darwin defendia que a racionalidade é um produto adaptativo da natureza, e não uma faculdade dada por Deus, para melhor compreensão da sua divindade (SINHA, 1988; ASCH, 1992).

A influência de Darwin na constituição da Psicologia do Desenvolvimento se fez presente, direta e indiretamente, por meio de seus discípulos, amigos e colegas, como Baldwin e Stanley Hall, por exemplo. Por isso é possível afirmar, como o faz sinHA (1988), que os grandes teóricos do desenvolvimento psicológico levaram em conta, na formulação de suas teorias, dois pontos comuns: 1/ uma abordagem comparativa, histórica e evolucionária para a psicologia humana; 2/ uma base científica profundamente influenciada pela tese da "recapitulação", como formulada por Ernst Haechel (1874, apud SINHA, 1988). Em outros termos, a ontogênese era vista como a chave para desvendar os segredos da "evolução mental", incluindo a evolução da linguagem e da simbolização, cabendo então à Psicologia acessar a "infância da raça" e formular as leis gerais do desenvolvimento mental e cultural.

Assim, pode-se dizer que dois dos teóricos que mais nos influenciam até hoje, Piaget e Vygotsky, comungam pelo menos três grandes teses: ambos sugerem a ausência de conceitos lógicos e científicos nas crianças pequenas; ambos salientam as diferenças mais do que as semelhanças entre as capacidades representacionais e simbólicas de crianças e de adultos e ambos propõem uma forma de construtivismo como alternativa ao empirismo e ao inatismo. A estas teses podem-se acrescentar mais duas: ambos vêem o desenvolvimento psicológico como uma forma de adaptação, PIAGET definindo literalmente que a inteligência é adaptação (1987) e vYGOTSKY (1987) entendendo que evolução da infância não é um ponto terminal da evolução biológica, mas um momento inaugural crucial da socialização biológica e ambos o consideram crucial para o desenvolvimento humano, a formação e o emprego de significados, ou seja, da abstração. 
Portanto, pode-se apontar uma tese consensual na Psicologia do Desenvolvimento: o ser humano vivo constrói permanentemente seu desenvolvimento, por meio da interação entre a sua atividade psicológica individual e o conjunto das atividades que contextualizam um meio sociocultural particular. O que distingue a atividade humana da animal é a natureza da atividade semântica: como já salientava LENY, em 1975, para compreendê-la, é necessário considerar que gênese e funcionamento guardam estreitas relações dialéticas e não podem ser compreendidos um sem o outro, isto é, a gênese e o funcionamento refletem os modos de apreensão do real pela atividade psicológica humana em geral, que os coloca em relação com o conjunto do sistema cognitivo, tal qual ele é, ele próprio forjado pela ação sobre o meio físico e social.

Dito em outros termos, podem-se considerar os pressupostos básicos da Psicologia do Desenvolvimento como pressupostos absolutamente otimistas. Nesse trabalho, como será esclarecido mais adiante, defende-se que se recuperem tais pressupostos nos estudos sobre os sujeitos portadores de deficiências. Como se sabe, a tendência geral destes estudos é centrar-se no modelo médico e, portanto, na lesão, de modo que os dados referem-se prioritariamente às suas implicações em termos das diferenças e incapacidades, e, conseqüentemente, como já apontado no caso da surdez (CADER; FÁVERO, 2000; FÁVERO; PIMENTA, 2002) e no caso da paralisia cerebral (SALIM; FÁVERO, 2001), os estudos geram poucos dados que evidenciem as particularidades do funcionamento cognitivo, lingüístico, representacional e socioemocional do sujeito, e o que estas particularidades podem representar do ponto de vista do desenvolvimento de novas competências (HODAPP; ZIGLER, 1995). No caso dos estudos sobre o sujeito portador da Síndrome de Down (SD), de um modo geral, como será mencionado a seguir, o quadro não é diferente.

Descrita pela primeira vez em 1967, por John Langdon Down, a SD é relacionada a três subgrupos de anomalias genéticas, conforme descritas por RONDAL (1993), todas elas trazendo a deficiência mental como uma das implicações: o primeiro diz respeito à trissomia do 21 , isto é, à presença de três cromossomos 21 ao invés de dois em todas as células do corpo, ocorrendo em $95 \%$ dos casos. O segundo refere-se à translocação, isto é, a ocorrência de material cromossômico 21 extra em todas as células, porém ligado a outro par cromossômico, que não o par 21 , verificada em aproximadamente $4 \%$ dos casos. O terceiro caso é denominado mosaicismo, isto é, encontra-se variação no número extra de cromossomos $21 \mathrm{em}$ determinadas células, sendo que outras são normais, comprovado em cerca de $1 \%$ dos casos. 
A SD pode ser considerada o tipo de retardo mental mais investigado, sobretudo pela sua alta incidência: 1 para cada 800 indivíduos nascidos vivos são portadores de SD (RONDAL, 1993). No Brasil, de acordo com uma pesquisa nacional, coordenada pela Federação Brasileira das Associações de SD (2000), há cerca de 110 mil pessoas com a SD.

Apesar da grande massa de estudos, a ênfase, em sua grande maioria, é no estabelecimento de correlações quantitativas sobre as diferenças de desempenho dos sujeitos com SD, segundo uma abordagem psicométrica, utilizando-se testes padronizados para crianças normais e que não sofrem adaptações em sua análise, de modo que o mesmo instrumento é utilizado para aferir a mesma função em sujeitos cuja capacidade de expressão é operacionalmente diferente, sem que isso seja considerado uma variável que torna óbvio o resultado da pesquisa (WAGNER; GANIBAN; CICHETTI, 1995). É assim que, embora o livro editado por CICHETTI e BEEGHLY (1995) se denomine Children with Down syndrome: a developmental perspective, os resultados das pesquisas são descritos com base em pontuações que são obtidas tendo como parâmetro as descrições do comportamento dito normal, o que, em última análise, acaba por instalar um círculo vicioso: comprovar que os sujeitos em questão apresentam um desempenho abaixo do esperado, o que comprova, então, a deficiência mental.

Assim, não é de se espantar que, quando se trata da escolarização, a questão da aquisição dos conceitos matemáticos e as atividades matemáticas sejam vistas, a priori, tanto no meio escolar como no atendimento psicopedagógico, como algo difícil, se não inadequado para os sujeitos com SD. O trabalho de GELMAn e COHEN (1988) é uma exceção.

No Brasil, os Anais do II Congresso Brasileiro e I Encontro LatinoAmericano sobre Síndrome de Down (1997) dão alguns indícios: dos aproximadamente 200 estudos, apenas cerca de 5\% faziam referência ao desenvolvimento cognitivo como um processo dinâmico que pode ser influenciado por aspectos internos e externos ao indivíduo, e que portanto pode se construir por meio de processos educacionais efetivos. Desses, apenas três estudos fazem referência ao pensamento lógico matemático do sujeito com SD (CUNHA, 1997; TUNES et al., 1997; MOLINA, 1997), sem sugerir, no entanto, propostas efetivas de intervenção, visando à aquisição das diferentes áreas do conhecimento. Isto também é um fato na literatura internacional: ROGERS e COLEMAN (1994), por exemplo, afirmam que a maior parte dos pesquisadores admitem o consenso segundo o qual as crianças com SD apresentam mais dificuldades na aquisição das habilidades numéricas do que das habilidades de leitura e escrita. 
Como se sabe, também nas primeiras séries do ensino regular a aquisição do conceito de número e da lógica do sistema numérico apresenta-se como um processo difícil, longo e complexo, ao mesmo tempo em que é fundamental para as aquisições conceituais futuras (ARTIGUE et al., 1994). Uma das dificuldades principais é que a transposição dos dados obtidos por meio de pesquisas para a prática das situações de aprendizagem em sala de aula não é algo simples, nem nas situações que envolvem adultos, o que, por princípio, deveria ser mais fácil (FÁVERO; SOARES, 2002). Dito em outros termos, apesar do avanço das pesquisas da chamada Psicologia da Educação Matemática, ainda há uma distância significativa entre os dados obtidos nas pesquisas e o que eles ensinam sobre os processos de aquisição, e a prática adotada nas salas de aula. Via de regra, os alunos, independentemente da idade e do grau de ensino, são treinados a resolver problemas, nos diferentes tópicos da matemática, segundo determinadas regras que devem ser memorizadas, de tal modo que a prática de ensino, no geral, privilegia a memorização, em detrimento da compreensão conceitual (STARKEY; GELMAN, 1982; TEIXEIRA, 1994; TEIXEIRA, 2000). Por isso mesmo, o consenso entre os professores, independentemente do grau de ensino, sobre o que definiria o bom aluno em matemática, faz referência à motivação, disciplina, atenção, e explica as dificuldades de aprendizagem, sobretudo em referência a uma suposta "falta de base" advinda das séries anteriores (FÁVERO, 1994). Este paradigma é tão partilhado no contexto escolar que os professores de Física, por exemplo, também o adotam e explicam as dificuldades na aprendizagem de Física referindo-se às "dificuldades com a matemática" (FÁVERO; SOUZA, 2001).

Por outro lado, as pesquisas sobre os chamados distúrbios de cálculo centram-se, na sua maioria, nas explicações de ordem psiconeurológica. Exemplos disto é a chamada alexia e agrafia para números, entendidos como a incapacidade de ler e escrever os números e a incapacidade de realizar cálculos, vistos como decorrentes da dificuldade na manipulação simbólica do sistema numérico, causada por uma disfunção do hemisfério esquerdo. Outro exemplo é a discalculia espacial, considerada como a incapacidade de respeitar as relações espaciais nas operações de cálculo (por exemplo, colocar os números em colunas) e relacionada, em geral, a uma lesão no hemisfério direito (GEARY, 1995). Na verdade, tais pesquisas são de pouca valia para a compreensão do desenvolvimento do portador de SD.

Portanto, articular a questão da aquisição conceitual da matemática com o desenvolvimento do sujeito portador de SD é uma tarefa no mínimo desafiante. Com o intuito de assumir esse desafio, o estudo que se relata aqui é fruto de uma proposta de mudança radical, segundo dois eixos principais: 
em primeiro lugar, considerar o desenvolvimento do sujeito portador de deficiência, e as peculiaridades deste desenvolvimento; e, em segundo lugar, centrar as investigações sobre a aquisição dos conceitos matemáticos, tendo por método de investigação a intervenção psicopedagógica, o que significa considerar a atividade mediada.

Esta proposta, como defendida por FÁvero (2002), requer três tarefas distintas e articuladas: uma avaliação das competências matemáticas do sujeito e de suas dificuldades; a sistematização de cada uma das sessões de trabalho, em termos de objetivos e descrição das atividades propostas; e uma análise minuciosa do desenvolvimento das atividades para cada sessão, explicitando: a seqüência de ações do sujeito; o significado destas ações em relação às suas aquisições de estruturas conceituais; o tipo de mediação estabelecida entre o adulto e o sujeito.

Trata-se, assim, de uma proposta que articula a intervenção e a pesquisa, numa abordagem cognitivo-desenvolvimental, como proposto no estudo descrito por FÁVERO e SOARES (2002), e que fundamenta um procedimento de tutoramento em situação de interação, com um duplo objetivo: proporcionar a ocasião para o sujeito desenvolver novos esquemas cognitivos e, ao mesmo tempo, colocar em evidência o processo desse desenvolvimento.

Para tanto, recuperaram-se alguns dados essenciais à compreensão do desenvolvimento do raciocínio lógico-matemático.

Como se sabe, PIAGET e SZEMINSKA (1975) foram os defensores da tese segundo a qual a noção numérica é uma construção primária da criança. Os estudos posteriores redimensionaram a variável tempo de aquisição, ao mesmo tempo em que aprofundaram e sistematizaram alguns dos conceitos piagetianos.

BRYANT (1995) ressalta duas importantes conclusões dos estudos de PIAGET e SZEMINSKA: a primeira é que a criança não tem, a princípio, a compreensão da propriedade de cardinalidade do número; a segunda é que uma criança que conta os cinco elementos de dois conjuntos, e, apesar dessa contagem, diz que aquele no qual a distância entre os elementos é visualmente maior tem mais elementos, não tem de fato a compreensão do significado da palavra "cinco".

Nesta mesma linha de raciocínio, GELMAN e GALLISTEL (1978), propuseram dois tipos de habilidades numéricas que podem ser desenvolvidos durante a primeira infância: a capacidade de abstração numérica e a capacidade de raciocínio numérico. A primeira refere-se à capacidade de representar uma quantidade em um conjunto, como, por exemplo, a contagem oral, com a finalização de uma quantidade totalizando o conjunto. A segunda refere-se à 
capacidade de operar sobre os conjuntos ou transformá-los de várias maneiras, isto é, ter a noção de que a disposição dos elementos de um conjunto não altera sua quantidade, mas que acrescentar ou tirar elementos desse conjunto o transforma. Em resumo, as habilidades de abstração ajudam a criança a estabelecer valores numéricos enquanto os princípios de raciocínio ajudam-na a fazer inferências e operar sobre os valores numéricos assim estabelecidos.

Portanto, a aquisição do conceito de número é, como diz VERGNAUD (1986), um conceito que necessita de muito fôlego e que ilustra várias idéias essenciais para a psicologia das atividades cognitivas superiores: mostra, de um lado, o longo tempo necessário à construção e apropriação dos conhecimentos, a diversidade de conceitos associados e hierarquizados e o caráter progressivo na complexidade destas aquisições. De outro lado, ilustra, teoricamente, a interseção entre a psicologia cognitiva e a epistemologia dos saberes e do saber-fazer.

Piagetiano por formação, e portanto adotando uma abordagem desenvolvimental, vERGNAUD (1986) defende que os conhecimentos atuais do sujeito procedem da interação entre sua experiência e seus conhecimentos anteriores (tese interacionista), e que o conhecimento procede, fundamentalmente, da ação do indivíduo sobre o mundo, uma vez que é sobretudo mediante a ação que o sujeito põe à prova seus conhecimentos e os modifica (tese operatória). Enfatizando a afirmação de que é a ação na situação que dá origem à elaboração conceitual, vergnaud $(1988 ; 1990)$ propôs a "Teoria dos Campos Conceituais", que procura estabelecer as relações entre os saberes constituídos socialmente e a construção do conhecimento pelo sujeito.

Analisando essa tese, MORO (1998) ressalta suas principais proposições: o conhecimento tem função adaptadora, logo um conceito só faz sentido para a criança se for contextualizado em uma situação-problema; o estudo psicogenético da aquisição dos conceitos exige o exame de diversos conceitos, de forma ampla, e em suas correspondências em diversas situações, de modo a se tecer uma rede, sem uma temporalidade pré-determinada; toda construção conceitual supõe, portanto, a elaboração de um conjunto de representações simbólicas que se relacionam entre si, diferenciando, no entanto, o que é o conceito e o que é a sua representação, isto é, estabelecendo a diferença entre quais são os significados conceituais e quais os sistemas de significantes que os identificam.

Dois conceitos piagetianos são retomados na proposta de VERGNAUD (1988; 1990): o de esquema e o de invariantes operatórios. Para analisar os invariantes operatórios, esse autor propõe dois outros conceitos: os teoremasem-ato, e os conceitos-em-ato. 
O conceito de esquema funciona como unidade de análise das ações em uma situação. Portanto, quando a situação está dominada pelo sujeito, o esquema se organiza de forma invariante como conduta dessa situação; quando, ao contrário, a situação não está dominada, ocorrerá um novo esquema a partir da transformação do anterior. Assim, em sua gênese o esquema é invariante, dinâmico, universal, e temporal, contendo, ainda, componentes indispensáveis (fins, regras, possibilidades e invariantes operatórios). Os teoremas-emato designam as propriedades das relações encontradas pelo sujeito quando age sobre a realidade e resolve uma situação-problema. Trata-se de uma informação, falsa ou verdadeira, que poderia ter sido descoberta pelo sujeito, sem intervenção do outro. Os conceitos-em-ato são as noções que o sujeito possui para resolver o problema, a respeito dos componentes dos teoremasem-ato. Só são constituídos na ação, pois dessa forma desempenham sua função: sugerem uma proposição, e, para que tenham sentido, necessariamente têm que ser verdadeiros. Em princípio, esta condição de verdade é sinalizada pelo outro. No processo de desenvolvimento, os teoremas-em-ato se automatizam com o tempo, mas essa automatização não impede que o sujeito tenha o controle das condições sob as quais está operando, e se elas são ou não adequadas. A partir dos conceitos-em-ato, todas as ações podem comportar uma parte de automatismo, e outra de decisão consciente.

Portanto, segundo vergnaud (1988; 1990), um conceito se define no seguinte tripé: a referência, ou o conjunto de situações que dão sentido ao conceito; o significado, ou o conjunto de invariantes que constituem as propriedades do conceito, e o significante, isto é, o conjunto de formas simbólicas ou lingüísticas que permitem a representação do conceito. Assim, os Campos Conceituais seriam "o conjunto de situações cujo domínio requer variedade de conceitos, de procedimentos e de representações simbólicas em estreita conexão" (VERGNAUd, 1990, p. 62).

Nessa perspectiva, é possível analisar o significado das aquisições, do ponto de vista do desenvolvimento psicológico. No que diz respeito ao conceito de número, a criança começa a lhe atribuir significado, dando-lhe um valor funcional, através da comparação, da combinação ou da transformação de coleções discretas. O significado do número fica explícito na tarefa de relacionar quantidades, por meio de questões simples do cotidiano, como por exemplo: quem ganhou mais? (comparação); quanto você tem a mais? (comparação); quanto nós temos juntos? (combinação); com quanto você ficou depois que: ganhou, perdeu, ou deu? (transformação de quantidades). Assim, a cardinalidade e a adição, os dois critérios mais importantes na construção do conceito de número, vão se estabelecendo. A cardinalidade pode ser ob- 
servada na repetição da última palavra numa contagem (um, dois, três, quatro; quatro!); ou na ênfase da última palavra numa contagem como um total particular (um, dois, três, quatro!); ou ainda, na resposta quatro, à pergunta "quanto?", sem necessariamente haver uma nova contagem do conjunto. A adição pode ser observada no uso do axioma fundamental da teoria da medida; trata-se, portanto, de um teorema-em-ato. Por exemplo, para a situação quatro mais três é igual a sete $(4+3=7)$, podemos contar as duas partes quatro e três (A U B) juntando as quantidades $(1,2,3,4 . .5,6,7)$, ou contar para a frente a partir do primeiro algarismo (A) a quantidade de elementos que há no segundo (B), (4...5, 6, 7). Ao fazer isto, as crianças utilizam, implicitamente, o "homomorfismo", isto é, a preservação da operação, de um contexto em outro, em um único sentido. Em um momento, a criança opera utilizando o conceito de união, e em outro momento, ela opera utilizado o conceito de números inteiros, munindo-se da adição e construindo um conceito-em-ato.

Além disso, a criança deve se apropriar dos conhecimentos diversos sobre o número, como a pesquisa do estado final pela contagem, seja para frente ou para trás. Sendo capaz de percorrer estes caminhos, germina, então, uma das competências associadas à gênese do número: a conservação de quantidades. A partir da conservação de quantidades, e do contato inicial com os fatos fundamentais da adição e subtração, a criança é capaz de reconhecer a equivalência existente entre a contagem para frente, a partir do primeiro número e da contagem para frente, a partir do número maior. No exemplo acima, $3+4=$ ?, seria contando a partir do primeiro número menor (3), para chegar no resultado $(3 ; \ldots 4,5,6,7)$ sete; ou contando a partir do número maior (4), para chegar ao resultado $(4 ; \ldots 5,6,7)$ sete. A utilização do segundo procedimento é mais econômica e implica na compreensão da propriedade comutativa da adição, ou seja, $3+4=4+3$, a comutatividade-em-ato.

Esse pequeno resumo teve como finalidades dois pontos essenciais ao estudo que será relatado a seguir: expor o nível de complexidade envolvido na construção de estruturas mentais na aquisição da lógica do sistema numérico e defender a necessidade de se conhecer como o sujeito com SD constrói estas estruturas, de modo que seja possível a elaboração de procedimentos psicopedagógicos que privilegiem a sua capacidade de desenvolver estruturas cognitivas visando à aquisição de conceitos matemáticos. 


\section{Método}

Para responder à proposta acima, desenvolveu-se um estudo de caso (WALLACE, 1989) centrado num sujeito com SD, já incluído em classe regular na Rede Oficial de Ensino do DF, cursando a terceira série e encaminhado ao atendimento psicopedagógico, com base na queixa de que ele não estava acompanhando a sua classe, apresentando dificuldades de aprendizagem, tais como as trocas de fonemas, as dificuldades de interpretação de textos e de resolução de problemas escritos de matemática, a ilegibilidade da sua caligrafia. $\mathrm{O}$ sujeito tinha 10 anos de idade quando o estudo se iniciou e não apresentava distúrbios de linguagem. Sua professora se referia a determinadas alterações de comportamento, tais como fugir da sala de aula, recusar-se a participar de atividades propostas, não finalizar tarefas, "emburrar", etc.

A anamnese informava que $\mathrm{S}$ era o $2^{\circ}$ filho, concebido quando a mãe contava 42 anos e seu primeiro filho, 20 anos. A gravidez transcorreu tranqüilamente e o parto foi normal, a termo, e a criança nasceu bem. Após a $1^{\mathrm{a}}$ semana, os pais foram informados do diagnóstico da Síndrome de Down (trissomia simples).

Nosso procedimento desenvolveu-se em quatro grandes fases: os primeiros contatos e o contrato de trabalho; a avaliação do sujeito; a intervenção; e a avaliação pós-intervenção. Embora o sujeito ainda esteja em atendimento psicopedagógico, para a sistematização desse estudo essas quatro fases abrangeram um total de 40 sessões gravadas em vídeo e transcritas, com duração de 30 minutos cada, 1 vez por semana, em média, abrangendo um período de tempo de quase um ano. Houve duas interrupções na seqüência dos atendimentos, nos períodos de 15 de dezembro de 2000 a fevereiro de 2001, e a segunda quinzena de julho de 2001.

A avaliação inicial do sujeito se desenvolveu em três etapas. Na primeira, utilizou-se a Prova Conceitual de Resolução de Problemas Numéricos - ECPN (GROUPE CIMETE, 1995), particularmente destinada a crianças com dificuldades de aprendizagem em matemática e na qual são explorados o conceito de número e suas propriedades, o que permite que se pesquise ao mesmo tempo a dependência entre as competências e entre as dificuldades e as bases independentes sobre as quais repousa uma competência complexa. $\mathrm{O}$ material se constitui de 40 fichas idênticas, três figurinhas (um gato, um cachorro e um coelho, por exemplo) e uma caixa para reserva de fichas.

Na segunda etapa, nos inspiramos no trabalho de MELJAC (1979) para propor as seguintes provas: 
- a utilização espontânea do número, com o objetivo é verificar como a criança estima e compara a quantidade de 4 conjuntos: um de 9 bonecos recortados em papel cartão, um de 20 conjuntos de roupas, um de 20 bonés, e um de 30 sapatos não lateralizados.

- a prova de comparação com o objetivo de avaliar como a criança compara as quantidades entre dois conjuntos, 11 círculos azuis e 11 círculos vermelhos, e que meios utiliza para igualar essas quantidades.

- a prova da constatação, com o objetivo de verificar se a criança constata que as quantidades não se alteram em função da forma que se dispõem os elementos de um conjunto dado, no caso círculos redondos azuis de 1,5cm de diâmetro, dispostos de três modos diferentes: em "desordem", em "boa forma" e em linha, para quantidades diferentes.

- a prova de conservação termo a termo, com o objetivo de verificar se o sujeito necessita fazer o pareamento termo a termo para comparar as quantidades, como garrafinhas plásticas e suas tampinhas, ou se elas são percebidas pela simples constatação.

$\mathrm{Na}$ terceira etapa da avaliação, apresentamos ao sujeito tarefas por escrito, semelhantes àquelas apresentadas na sala de aula da $3^{\mathrm{a}}$ série e centradas na adição e na subtração. Todas as sessões referentes a essas três etapas foram gravadas em vídeo, transcritas e analisadas.

As sessões de intervenção, terceira fase do estudo, foram planejadas com base nos dados obtidos na fase de avaliação, e tinham, como já dito, o objetivo geral de propor e desenvolver atividades com o sujeito que lhe propiciassem a construção do conceito de número e da lógica do sistema numérico, de acordo com um procedimento de intervenção de caráter cognitivo desenvolvimental. Assim, a análise do desenvolvimento de uma sessão fundamentava o planejamento de uma ou mais sessões seguintes. O material utilizado para cada situação proposta era compatível com o objetivo geral da intervenção e com o objetivo particular de cada sessão: materiais para atividades gráficas (lápis, borracha, régua, canetas hidrocor, cola branca, cola de isopor, tesoura, papel ofício, cartolina, folha de isopor, etiquetas adesivas, etc.); materiais psicopedagógicos (blocos lógicos, recortes em cartolina, fichas diversas); sucata (garrafinhas plásticas vazias com tampas, pedrinhas, tampinhas de metal, lacre metálico de latinhas, etc.); jogos diversos (Vila Kit, dominó, dados, cartas de baralho, Duo, etc.).

Apresenta-se no quadro abaixo, a título de ilustração, um pequeno trecho transcrito de uma das sessões, cuja atividade consistia em tirar as pedrinhas de dentro de 12 garrafinhas plásticas transparentes, contá-las, recolocálas dentro de cada garrafa, escrever o número da quantidade em etiquetas e colar do lado de fora das garrafas correspondentes. 
QUADRO 1 - TRECHO DA TRANSCRIÇÃO DE UMA SESSÃO DE INTERVENÇÃO MATERIAL - 12 GARRAFINHAS TRANSPARENTES, PEDRINHAS, ETIQUETAS ADESIVAS.

\begin{tabular}{|c|c|c|}
\hline Exper. & Sujeito & Análise do desempenho \\
\hline E propõe a atividade & $\begin{array}{l}\text { S : Pega a primeira garrafa, despeja } \\
\text { as pedras sobre a mesa e as conta } \\
\text { uma a uma, "1, } 2,3,4 \text { ". Escreve } 4 \text { na } \\
\text { etiqueta. } \\
\text { S: Pega a segunda garrafa, olha } \\
\text { para E e diz: "Não tem nada." }\end{array}$ & $\begin{array}{l}\text { S utiliza a contagem termo a } \\
\text { termo e quantifica por escrito, } \\
\text { com o algarismo } 4 \text { ao final da } \\
\text { contagem. }\end{array}$ \\
\hline $\begin{array}{l}\text { E : "O que você vai } \\
\text { escrever para indicar } \\
\text { isso?" }\end{array}$ & $\begin{array}{l}\text { S: “Zero.” (escreve o algarismo) } \\
\text { "Por que você não colocou nada } \\
\text { dentro?" }\end{array}$ & $\begin{array}{l}\text { S reconhece que o algarismo } \\
\text { zero representa a ausência de } \\
\text { elementos. }\end{array}$ \\
\hline $\begin{array}{l}\text { E : "Porque eu quis } \\
\text { deixá-la vazia." }\end{array}$ & $\begin{array}{l}\text { - Conta " } 1,2,3 \text { ", marca três na } \\
\text { etiqueta. } \\
\text { - Conta " } 1,2,3,4,5,6,7 \text { ", marca } \\
\text { sete na etiqueta. } \\
\text { - Olha a quantidade de pedras, } \\
\text { despeja e marca } 1 \text { na etiqueta. } \\
\text { - Olha a quantidade, despeja e marca } \\
5 \text { na etiqueta, sem contar. } \\
\text { S prossegue contando as pedrinhas e } \\
\text { colocando as etiquetas. } \\
\text { - Conta " } 1,2,3,4,5,6,7,8 \text { " e } \\
\text { marca oito na etiqueta. } \\
\text { - Vê a garrafa vazia e marca zero na } \\
\text { etiqueta. } \\
\text { - Olha a quantidade, despeja e marca } \\
2 \text { na etiqueta, sem contar. } \\
\text { S conta as pedrinhas: " } 1,2,3,4,5, \\
6,7,8,9 . " \text { E pergunta para E: } \\
\text { "quantas mesmo?" }\end{array}$ & $\begin{array}{l}\mathrm{S} \text { totaliza as quantidades por } \\
\text { meio da contagem termo a } \\
\text { termo e por meio da } \\
\text { estimativa visual, registrando } \\
\text { sempre o total de forma } \\
\text { escrita utilizando-se do } \\
\text { algarismo apropriado. }\end{array}$ \\
\hline $\begin{array}{l}\text { E: "Você que contou... } \\
\text { quantas?" }\end{array}$ & $\begin{array}{l}\text { S: "Tenho que contar de novo? } 1,2 \text {, } \\
3,4,5,6,7,8,9 . " \text { S escreve na } \\
\text { etiqueta: } 9 \\
\text { S escreve os algarismos e diz: "Está } \\
\text { certo?" }\end{array}$ & $\begin{array}{l}\text { S não lembra o número final } \\
\text { que totaliza a contagem. }\end{array}$ \\
\hline $\begin{array}{l}\text { E: "Está." } \\
\text { E : "Agora organize as } \\
\text { garrafas da que tem } \\
\text { menos pedrinhas, para } \\
\text { aquela que tem mais." } \\
\text { "Escreva no papel os } \\
\text { números do menor para } \\
\text { o maior." }(*) .\end{array}$ & $\begin{array}{l}\mathrm{S} \text { conta " } 1,2,3,4,5,6 \text { " e marca } 6 \\
\text { na etiqueta. } \\
\mathrm{S}-\text { "Você vai fazer o que com isso?" }\end{array}$ & \\
\hline $\begin{array}{l}\text { E: "O que você quer } \\
\text { que eu faça?" }\end{array}$ & S - "Pregue na parede." & \\
\hline
\end{tabular}

${ }^{*}$ ) no papel estavam desenhadas as garrafinhas sem ordenação ou numeração 


\section{Resultados}

O desempenho do sujeito na Prova ECPN da primeira fase da avaliação foi bastante aquém daquele esperado de um aluno que freqüentava a $3^{\mathrm{a}}$ série. As dificuldades do sujeito nas provas mostraram que ele não tinha o conceito de número. Portanto, o sujeito precisava construir esquemas que lhe possibilitassem usar o número como representação, nos dois critérios da construção do número: na cardinalidade e na adição.

O desempenho do sujeito no conjunto das provas da avaliação também deixou claro que, nas tarefas escolares que requeriam a operação com quantidades, ele apenas seguia certas regras da notação e, mesmo quando se utilizava dos dedos como elementos de contagem, o sujeito não representava a quantidade anunciada como algarismo na operação. Em quantidades pequenas, como por exemplo na operação $82+73$, ao somar as unidades $2+3$, o sujeito conseguiu juntar dois dedos de uma mão com três da outra e contar todos, obtendo cinco. Descrito assim, pode parecer que ele possuía o conceito de número, utilizando as funções de cardinalidade e o axioma para transformar quantidades discretas. No entanto, na continuidade da ação, verificou-se que o sujeito havia automatizado a quantidade de dois dedos e a quantidade de três, usando um esquema que ele já possuía, isto é, de que aumentar significa juntar. Em outros termos, no fim da contagem, o sujeito não possuía um total em quantidade (cinco), e sim, cinco elementos ordenados (dedos). Na verdade, estávamos diante de um forte elemento da memorização do "como-sefaz", isto é, automaticamente o sujeito resolvia a operação de cima-para-baixo e da esquerda-para-a-direita, mas tal ação não implicava no conhecimento de que tal movimento relacionava-se ao nosso sistema de numeração; tratava-se da memorização de um "jeito-de-fazer". Verificou-se também que o sujeito possuía as noções convencionadas associadas aos sinais gráficos de / +/, juntar e /-/ tirar, só que essas noções haviam sido memorizadas e não construídas, uma vez que elas não se traduziam em um conceito-em-ato. Tais conclusões foram reafirmadas no desempenho do sujeito frente à prova de comparação entre o número de garrafas e o número de tampas: embora a quantidade de elementos fosse pequena, o sujeito demonstrou a necessidade de constatação termo a termo, mesmo quando a quantidade de tampinhas e garrafas era significativamente diferente, como, por exemplo, no caso de oito tampinhas para cinco garrafas. Outro aspecto que merece ser sublinhado é que durante essa prova o sujeito ressaltava, constantemente, o que estaria "faltando" e não o que estaria "sobrando". Por exemplo, no caso de sete tampi- 
nhas e cinco garrafas, ele dizia que estavam faltando garrafas, e não sobrando tampinhas. Pode-se pensar que isso era um indício de que naquele momento, última sessão da fase de avaliação, um esquema de adição estivesse se reorganizando (a parte que falta para completar o todo), uma vez que referir-se à falta de elementos pode significar a compreensão da composição do conjunto como um todo.

Resumindo, os dados da avaliação mostraram que: o sujeito quantificava até seis e, a partir desta quantidade, passava a utilizar o conceito de "muitos", sem demonstrar estabelecer a relação entre número e quantidade; o sujeito não comparava conjuntos e, diante de uma tarefa de equivalência pela comparação, ele utilizava o pareamento termo a termo; o sujeito associava "mais que" ao aumento de quantidade e "menos que" à diminuição de quantidade, sem apresentar ainda estratégias adequadas à alteração de quantidade com variação de (x) números de elementos para mais ou para menos; o sujeito utilizava a contagem com o intuito de quantificar, mas não conduzia a função de cardinalidade numérica pela contagem de modo correto, apresentando dificuldade em conduzi-la, ora por omissão de elementos, ora por ampliação da quantidade efetiva, contando mais elementos do que os presentes; o desempenho do sujeito mostrava ações mecanicamente desenvolvidas, sem qualquer indicação de que ele pudesse descrever com palavras como ou por que estava desenvolvendo aquele procedimento em particular; o sujeito resolvia operações com números com base em regras aplicadas aos cálculos de adição e subtração, sem demonstrar conhecer o sistema de numeração decimal. $\mathrm{Ou}$ seja, o sujeito, como dito antes, não tinha construído o conceito de número e a lógica do sistema numérico, e foi esse dado que fundamentou a intervenção.

A análise dos dados obtidos durante a intervenção indicaram algumas particularidades do sujeito com SD. A primeira delas diz respeito à atividade de contagem: de início, o sujeito necessita organizar espacialmente os elementos de um conjunto, dando um certo distanciamento entre um e outro para quantificá-los, estratégia que diminui a probabilidade de erros; seu pensamento lógico está vinculado à percepção visual imediata, que ora facilita a quantificação por meio da estimativa visual no caso de conjuntos com até 6 elementos, ora a dificulta, uma vez que os conjuntos com mais de 6 elementos são percebidos como "muitos" indicando o tamanho do conjunto, e não propriamente a quantidade de elementos nele; o sujeito tem dificuldade de estabelecer uma velocidade de contagem que se ajuste ao seu procedimento: ora ele é muito veloz e prejudica a totalização, por omissão ou extensão do número de elementos quantificados, ora ele é muito lento e não consegue armazenar na memória de trabalho a totalização que estava processando; o 
sujeito apresenta uma associação direta entre o movimento do ato motor e o raciocínio lógico, uma vez que este movimento interfere diretamente em seu processo de contagem e totalização: em algumas situações, o sujeito conta os seus movimentos e não o número de elementos do conjunto que foi retirado com esse movimento; em outras, os movimentos realizados com as duas mãos simultaneamente são contados como apenas um, como se se tratasse de um movimento em bloco. Pode-se pensar que a atividade motora se sobrepunha à atividade de contagem.

Um dado novo em relação às pesquisas na área diz respeito à consciência do sujeito em relação às suas próprias dificuldades e a relação entre a tomada de consciência do sujeito sobre o aumento da complexidade da atividade proposta e um aumento na sua ansiedade para a realização desta atividade, o que levava a uma tentativa de aumentar a velocidade de seu desenvolvimento, como se o sujeito quisesse finalizá-la o mais rápido possível. Ou seja: a análise dos dados das sessões de intervenção sugerem o desenvolvimento de uma consciência metacognitiva no sujeito com SD, seja em relação à atividade proposta como em relação à sua própria capacidade para realizá-la. $\mathrm{O}$ sujeito também demonstra preocupação em responder aquilo que ele acredita que o adulto está solicitando, como se ele se visse sempre numa situação de avaliação.

Como sugerido em alguns estudos, o desempenho do sujeito indicava existir similaridade entre as aquisições dos seus esquemas operatórios e aqueles que são relatados para crianças sadias. No entanto, indicava também uma diferença na reestruturação desses esquemas, sugerindo que a estabilidade dos processos de acomodação e de assimilação ocorriam muito mais lentamente e que, se não houvesse uma mediação efetiva para a reestruturação, o esquema anteriormente estabilizado voltava a ser utilizado, caracterizando o que denominamos de rigidez mental.

No decorrer das sessões, as ações mecânicas do sujeito foram desaparecendo, sendo substituídas por ações reflexivas: observou-se a passagem das velhas estruturas anteriormente adquiridas para novos esquemas.

Um importante dado desse estudo diz respeito ao material psicopedagógico: ficou evidente que, como o sujeito apresentava uma construção de estruturas cognitivas sustentada em um pensamento concreto, a manipulação do material concreto era imprescindível para a formação e reestruturação desses esquemas. No entanto, vale salientar que só foi possível concluir sobre a adequação ou inadequação de determinados materiais porque as ações eram analisadas pari passu com o desenvolvimento das sessões. Assim, por exemplo, o fato referido acima do sujeito "se atropelar" na 
atividade de contagem indicou que não bastava a utilização de um material concreto, mas de um em particular, que apresentasse uma contingência tal que levasse o sujeito a controlar sua ação. Por isso utilizamos garrafinhas plásticas, em cujo gargalo só seria possível passar uma pedrinha de cada vez, controlando assim a contagem.

As provas referidas na avaliação do sujeito antes da intervenção propriamente dita foram utilizadas mais uma vez na fase da avaliação após a intervenção. Sua análise revelou indícios de progresso: o sujeito comparou conjuntos, ora utilizando a totalização por meio da contagem, ora utilizando a totalização por meio da estimativa visual; o sujeito demonstrou haver construído o conceito de número, uma vez que passou a utilizar as funções numéricas de cardinalizar e modificar a quantidade utilizando o axioma da adição; o sujeito utilizou o conceito de número para operar cálculos de adição e subtração, demonstrando uma compreensão incipiente do funcionamento do sistema de numeração decimal. Por outro lado, o sujeito ainda apresentou dificuldade no processo de contagem e essa dificuldade poderia estar associada à organização espacial dos elementos a serem contados e à velocidade com que o sujeito procurava desenvolver o processo. É importante salientar mais uma vez que essa velocidade aparecia mais freqüentemente quando o sujeito se percebia não capacitado para realizar uma determinada atividade, $o$ que, como já foi dito, sugere o desenvolvimento de uma consciência metacognitiva.

Em resumo, este estudo levanta pelo menos três questões que se relacionam entre si. A primeira diz respeito à contagem: para que ela contribua à aquisição do número, ela deve se transformar de contagem mecânica em automação da contagem, isto é, em um teorema-em-ato. A segunda questão diz respeito ao que chamamos de rigidez mental que, uma vez estabelecida, pode interferir na construção de esquemas operatórios, como se o sujeito se fixasse nos esquemas sensoriomotores, como era o caso do sujeito no início do estudo: ele não operava com números mas evidenciava um treinamento escolar utilizando os números mecanicamente. Isso pode explicar, em parte, tanto a rigidez dos esquemas, uma vez que o treino escolar não parece favorecer a sua reorganização, como também, e por implicação, o desenvolvimento mais lento nas aquisições das competências sensoriomotoras, pré-operatórias e operatórias.

A terceira questão diz respeito ao papel de mediação do adulto: cabe a ele analisar sua própria postura na interação com o sujeito, de modo que o seu próprio desejo de sucesso na intervenção não se traduza em pressão para aquele. Cabe-lhe ainda fundamentar e avaliar o progresso de seu trabalho por meio da 
combinação sistemática entre o desenvolvimento de competências para minimizar as dificuldades do outro e a criação de novas situações nas quais as competências desenvolvidas possam ser utilizadas, e assim sejam ampliadas. Como se vê, essas questões se relacionam com a escolaridade e com a competência do adulto, que é o professor.

Por fim, resta sublinhar a pertinência de se adotar, como proposto por FÁVERO (2002), a intervenção psicopedagógica como estratégia de pesquisa: em primeiro lugar, porque ela coloca em evidência o próprio processo de desenvolvimento, tanto no que se refere ao desenvolvimento do outro, como aquele do adulto que é o mediador; em segundo lugar, porque a exigência na sistematização da análise das sessões avalia a própria intervenção e, finalmente, em terceiro lugar, porque em assim sendo, ela gera subsídios para a orientação do professor que atua junto ao sujeito em questão.

\section{REFERÊNCIAS}

ARTIGUE, M. et al. Vingt ans de didactique des mathèmatiques en France. Grenoble: La Pensée Sauvage, 1994.

$\boldsymbol{A} \mathrm{SCH}, \mathrm{M}$. G. Historicizing mind science: discourse, practice, subjectivity. Science in Context, v. 5, n. 2, p. 193-207, 1992.

BRYANT, P. Children and Arithmetic. Journal of Child Psychology and Psychiatry, v. 36, n. 1, p. 3-32, 1995.

CADER, F. A. A. A.; FÁVERO, M. H. A mediação semiótica no processo de alfabetização dos surdos. Revista Brasileira de Educação Especial, v. 6, n. 1, p. 117-131, 2000.

CICCHETTI, D.; BEEGHLY, M. An organizational approach to the study of Down syndrome: contributions to an integrative theory of development. In: CICCHETTI, D; BEEGHLY, M. (Orgs.). Children with Down syndrome: a developmental perspective. Cambridge: Cambridge University Press, 1995, p. 29-62.

DA SEGREGAÇÃO à Integração um processo para a construção da cidadania. In: CONGRESSO BRASILEIRO E PRIMEIRO ENCONTRO LATINO-AMERICANO SOBRE SÍNDROME DE DOWN, 2., 1997. Anais ... Brasília.

CUNHA, N. H. S. O desenvolvimento do pensamento lógico. CONGRESSO BRASILEIRO E PRIMEIRO ENCONTRO LATINO-AMERICANO SOBRE SÍNDROME DE DOWN, 2., 1997. Anais ... Brasília, p. 149. 
FÁVERO, M. H. O valor sócio-cultural dos objetos e a natureza sócio-cultural das ações humanas: a mediação exercida pelo meio escolar no desenvolvimento e na construção do conhecimento. CONGRESSO NACIONAL DE PSICOLOGIA ESCOLAR, 2., 1994, Campinas. Anais ... p. 58-61.

; SOUZA, C. M. S. G. Resolução de problemas em Física: revisão de pesquisa, análise e proposição metodológica. Investigação em Ensino de Ciências. Porto Alegre, v. 6, n. 2, 2001. <www.if.ufrgs.br/public/ensino/vol6/n2/15indice.htm>

. A aquisição da matemática e a intervenção psicopedagógica. Simpósio: deficientes uma articulação entre a teoria e a prática. CONGRESSO BRASILEIRO, PSICOLOGIA: CIÊNCIA E PROFISSÃO, 1., 2002, São Paulo: USP.

; SOARES, M. T. C. Iniciação escolar e a notação numérica: Uma questão para o estudo da desenvolvimento adulto. Psicologia: Teoria e Pesquisa, v. 18, n. 1, jan./abr. 2002, p. 43-50.

; PIMENTA, M. L. A aquisição de conceitos matemáticos pelos surdos: análise e reflexão. CONGRESSO SURDEZ E PÓS -MODERNIDADE: NOVOS RUMOS PARA A EDUCAÇÃO BRASILEIRA, 2002, Rio de Janeiro. Anais... Rio de Janeiro: INES, Instituto Nacional de Educação de Surdos, Divisão de Estudos e Pesquisas, p. 135-138.

FEDERAÇÃO BRASILEIRA DAS ASSOCIAÇÕES DE SÍNDROME DE DOWN. Síndrome de Down no Brasil: caminhando para o terceiro milênio. Brasília, 2000.

GELMAN, R.; COHEN, M. Qualitative differences in the way Down syndrome and normal children solve a novel counting problem. In: NADEL, L. (Org.). The Psycobiology of Down Syndrome. Cambridge: Mass, MIT Press, 1988.

GELMAN, R.; GALLISTEL, C. R. The children understanding of number. Cambrige. MA: Harvard University Press, 1978.

GEARY, D. C. Mathematical Disabilities: Cognitive, Neuropsychological and Genetic Componentes. Psychological Bulletin, v. 14, n. 2, p. 345-362, 1995.

GROUPE CIMETE. Compétences et incompétences en arithmétique. Une aide au diagnostic et à l'action pédagogique particullièrement destinée aux entants affectés de difficultés sévères d'apprentissage, 1995.

HODDAPP, R. M.; ZIGLER, E. Applying the developmental perspective to individuals with Down syndrome. In: CINCCHETTI, D.; BEEGHLY, M. Children with Down syndrome: a developmental perspective. Cambridge: Cambridge University Press, 1995, p. 1-28.

LENY, J. F. Sémantique et Psychology. Langages, 9 ème année, Paris, n. 40, p. 3-29, 1975. 
MELJAC, C. Décrire, Agir et Compter. Paris: PUF, 1976.

MORO, M. L F. M. Aprendizagem construtivista da adição/subtração e interações sociais - O percurso de três parceiros. Curitiba, 1998. Tese (Professor Titular de Psicologia da Educação) - Departamento de Teoria e Fundamentos da Educação, Setor de Educação, UFPR.

MOLINA, S. E. A estrutura cognitiva e o pensamento lógico-matemático na criança com Síndrome de Down: um enfoque desde a interdisciplinaridade e a transdisciplinaridade. In: CONGRESSO BRASILEIRO E PRIMEIRO ENCONTRO LATINO-AMERICANO SOBRE SÍNDROME DE DOWN, 2., 1997, Brasília. Anais ... p. 150.

PIAGET, J.; SZEMINSKA, A. A gênese do número na criança, Rio de Janeiro: Zahar, 1975.

O nascimento da inteligência na criança. Rio de Janeiro: Guanabara, 1987.

RONDAL, J. A. Down's syndrome. In: BISHOP, D.; MOGFORD, K. (Orgs.). Language development in exceptional circumstances. Hillsdale: Laurence Erlbaum, 1993, p. 165-176.

ROGERS, R. T.; COLEMAN, M. Atención médica en el Síndrome de Down, um planteamiento de medicina preventiva. Barcelona: Fundació Catalana Síndrome de Down, 1994.

SALIM, C. M. R.; FÁVERO, M. H. Análise cognitiva da paralisia cerebral: uso da análise qualitativa do WISC. Universitas: Psicologia, v. 2, n. 2, Brasília, 2002.

SINHA, C. Evolution and development, the phylocultural complex. In: Languague and representation. New York: University Press, 1988, p. 77-110.

STARKEY, P; GELMAN, R. The development of addition and subtraction abilities prior to formal schooling in arithmetic. In: CARPENTER, T. P.; MOSER, J. M; ROMBERG, T. A. (Eds.). Addition and subtraction: A cognitive perspective. Hillsdale, N. J.: Erlbaum, 1982, p. 99-115.

TEIXEIRA, L. R. M. Menos com menos dá mais ou menos? A aprendizagem aleatória dos números inteiros. In: Matemática. Coordenação: Ricardo de Souza, Angelo M. Martins e Maria Luiza C. Benedetti. São Paulo: FDE, n. 5, p. 205-212, 1994. Série Diário de Classe.

TEIXEIRA, L. R. M. As representações simbólicas e os significados construídos por alunos do ensino fundamental sobre a escrita numérica. Revista Nuances. Presidente Prudente: Unesp, v. 4, n. 6, p. 143-155, ISSN 141-398-55, 2000.

TUNES, E. et al. A Síndrome de Down e o desenvolvimento do pensamento lógicomatemático. In: CONGRESSO BRASILEIRO E PRIMEIRO ENCONTRO LATINOAMERICANO SOBRE SÍNDROME DE DOWN, 2., 1997, Brasília. Anais ... p. 149. 
VERGNAUD, G. El Niño, las Matemáticas y la Realidad: problemas de la enseñanza de las matemáticas en la escuela primaria. México: Editorial Trillas, 1991.

. Piaget y la Didactica: algunas ideas fundamentales de Piaget en torno a la didactica. Perspectivas, v. 26, n. 1, mar. 1986, p. 196-207.

Theoretical frameworks and empirical facts in the psychology of mathematics education. In: ICME, 6., 1998, Budapest. Annais...

. Psicologie du développement et didactique des mathématiques. Un exemple: les structures additives. Petit, v. 10, n. 22, p. 51-69, 1990.

. L'appropriation du concept de nombre: un processus de longue haleine. In: BIDEAU, J.; MELJAC, C.; FISHER, J. P. (Eds.). Les chemins du nombre. Lille, France: Presses Universitaires de Lille, p. 271-282, 1991.

VYGOSTKY, L. S. The Problem of Mental Retardation - A Tentative Working Hypothesis, Soviet Psycology, v. 1, n. 26, p. 78-86, 1987.

WAGNER, S.; GANIBAN, J.; CICHETTI, D. Attention, memory, and perception in infants with Down syndrome: a review and commentary. In: CICCHETTI, D.; BEEGHLY, M. (Orgs.). Children with Down syndrome: a developmental perspective. Cambridge: Cambridge University Press, 1995, p. 147-230.

WALLACE, D. B. Studying the individual: the case study method and other genres. Archives de Psychologie, n. 57, p. 69-90, 1989.

Texto recebido em 14 mar. 2003

Texto aprovado em 31 out. 2003 